\title{
Rhinal Cortex Removal Produces Amnesia for Preoperatively Learned Discrimination Problems But Fails to Disrupt Postoperative Acquisition and Retention in Rhesus Monkeys
}

\author{
Jennifer A. Thornton, ${ }^{1,2}$ Lawrence A. Rothblat, ${ }^{2}$ and Elisabeth A. Murray ${ }^{1}$ \\ ${ }^{1}$ Laboratory of Neuropsychology, National Institute of Mental Health, Bethesda, Maryland 20892, and 2Department of \\ Psychology, The George Washington University, Washington, DC 20052
}

\begin{abstract}
To test whether the rhinal cortex (i.e., entorhinal and perirhinal cortex) plays a time-limited role in information storage, eight rhesus monkeys were trained to criterion on two sets of 60 object discrimination problems, one set at each of two different time periods separated by 15 weeks. After the monkeys had learned both sets, two groups balanced for preoperative acquisition rates were formed. One group received bilateral ablation of the rhinal cortex $(n=4)$, and the other was retained as an unoperated control group $(n=4)$. After a 2 week rest period, monkeys were assessed for retention of the object discrimination problems. Retention was significantly poorer in monkeys with removals of the rhinal cortex relative to the controls (68 vs $91 \%)$. Although both groups showed slightly better retention of problems from the more recently learned set, there was no evidence of a differential effect of the cortical removal across
\end{abstract}

sets (i.e., no temporal gradient). In addition, the monkeys with rhinal cortex lesions subsequently learned three new sets of 10 object discrimination problems as quickly as the controls did, thus ruling out the possibility of a gross impairment in visual perception or discrimination abilities. Furthermore, they retained these postoperatively learned object discriminations as well as the controls did. The findings indicate that the rhinal cortex is critical for the storage and/or retrieval of object discrimination problems that were learned up to 16 weeks before rhinal cortex ablation; however, in the absence of the rhinal cortex, efficient learning and retention of new discrimination problems can still occur.

Key words: visual discrimination; stimulus memory; retrograde amnesia; entorhinal cortex; perirhinal cortex; rhesus monkey
Bilateral damage to the medial temporal lobe in humans typically results in a temporally graded retrograde amnesia, in which recent memories are lost although remote memories are spared, as well as severe anterograde amnesia, which is characterized by rapid forgetting of new information (e.g., Scoville and Milner, 1957). The phenomenon of temporally graded retrograde amnesia is consistent with the idea of memory consolidation (see McGaugh and Herz, 1972) and with the idea that the role of medial temporal lobe structures is only temporary. Presumably, as time passes after the original learning episode, memories that were initially dependent on these areas are eventually consolidated into a more permanent state elsewhere (for review, see Squire and Alvarez, 1995).

Zola-Morgan and Squire (1990) found that monkeys with damage to the hippocampal formation, entorhinal cortex, and parahippocampal cortex exhibited temporally graded retrograde amnesia, and they concluded that the hippocampal formation has a time-limited role in memory. Furthermore, similar findings have now been reported in rats (Winocur, 1990; Kim and Fanselow, 1992; cf. Bolhuis et al., 1994; Cho et al., 1995) and rabbits (Kim et al., 1995) after lesions of the hippocampal formation. Thus, it seems that the hippocampal formation acts as a temporary store

Received June 3, 1997; revised Aug. 13, 1997; accepted Aug. 15, 1997.

We thank Tinera Fobbs, Wendy Hadfield, Dino Peralta, and John Sewell for their valuable technical support, Norbert Vnek for helpful comments during the initial planning of these experiments, and Mortimer Mishkin, Mark Baxter, and Robert Hampton for comments on an earlier version of this manuscript.

Correspondence should be addressed to Dr. Elisabeth A. Murray, Laboratory of Neuropsychology, National Institute of Mental Health, Building 49, Room 1B80, 49 Convent Drive, Bethesda, MD 20892-4415.

Copyright (C) 1997 Society for Neuroscience $\quad 0270-6474 / 97 / 178536-14 \$ 05.00 / 0$ for at least some types of information, a picture that is consistent with clinical findings. However, it has recently been established in monkeys that the rhinal cortex (i.e., entorhinal and perirhinal cortex) and the hippocampal formation have dissociable roles in memory (Meunier et al., 1993; Murray et al., 1993; O'Boyle et al., 1993; Eacott et al., 1994; Gaffan, 1994a; Murray and Mishkin, 1996). If the rhinal cortex and the hippocampal formation have dissociable roles in the acquisition of information, as the foregoing studies suggest, they may also make independent contributions to the long-term storage of information. These considerations suggest that the role of the rhinal cortex in the retention of information should be evaluated separately from that of the hippocampus.

Accordingly, in Experiment 1 we examined the effect of rhinal cortex ablation on the retention of two sets of object discrimination problems learned at two different time periods [16 and 1 week(s)] before surgery. The 16 week training-surgery interval was chosen, in part, because it exceeds that at which hippocampectomized monkeys have been found to have intact retention of preoperatively learned discriminations (Zola-Morgan and Squire, 1990). If the rhinal cortex is critical for information storage or retrieval for only a limited period of time, as hypothesized, then the operated monkeys would exhibit good retention relative to controls of the object discrimination problems learned long before surgery but poor retention of the problems learned immediately before surgery. By contrast, if the rhinal cortex is critical for storage or retrieval over a longer period of time, then the operated monkeys would exhibit poor retention of the object discriminations learned at both time points.

In Experiment 2 we examined the effect of rhinal cortex abla- 


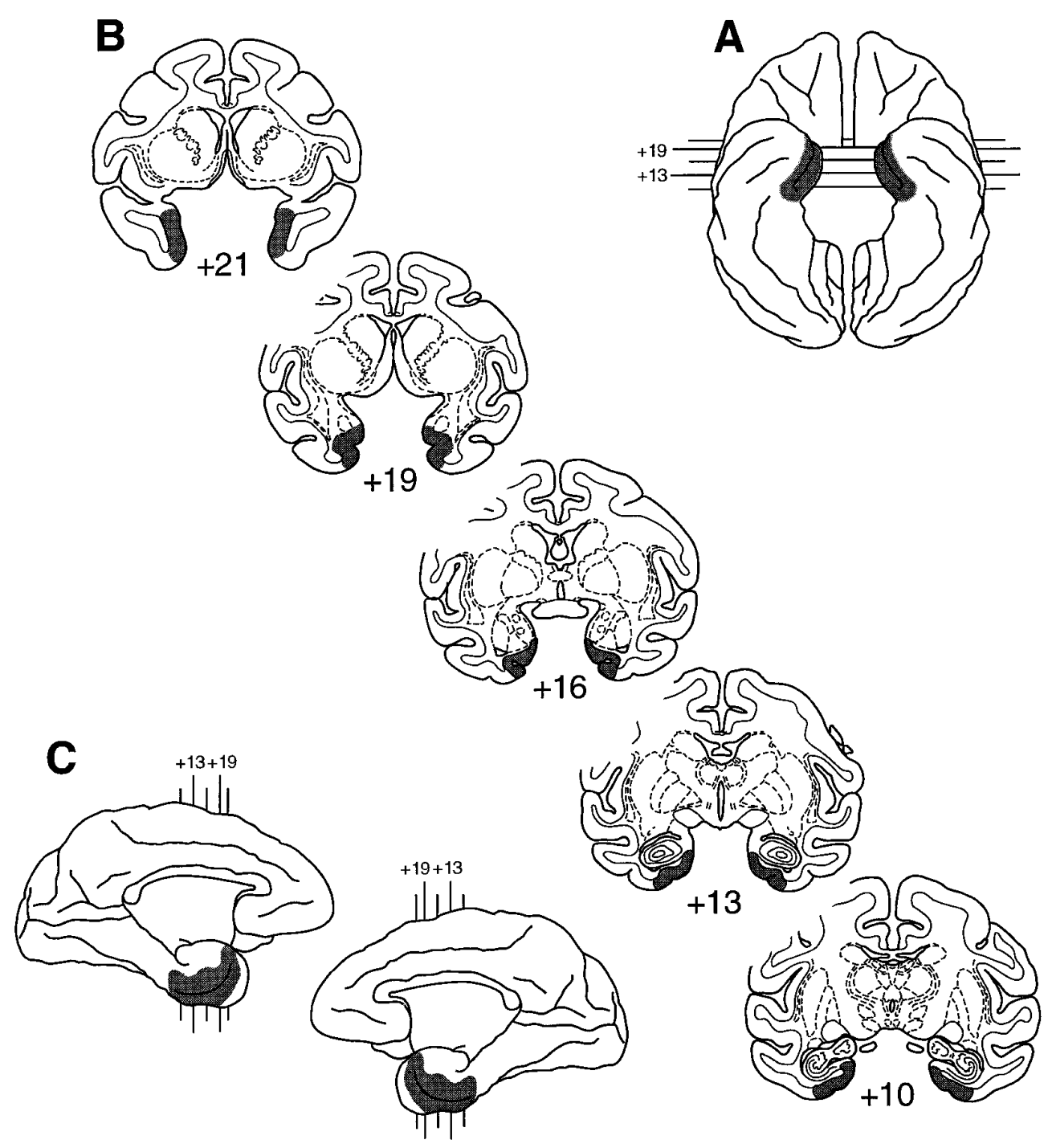

Figure 1. Shaded regions indicate the location and extent of the intended lesions of the rhinal cortex. $A$, Ventral view of a rhesus monkey brain. $B$, Coronal sections from levels through the temporal lobe in a rhesus monkey brain. $C$, Medial aspect of both hemispheres. The numerals indicate the distance in millimeters from the interaural plane. tion on acquisition and retention of postoperatively learned object discrimination problems. There were two main goals. First, we wanted to clarify the nature of the impairment, if any, that might be observed in Experiment 1. That is, if monkeys with rhinal cortex lesions were impaired in Experiment 1, it would be useful to assess their postoperative learning abilities with the same kinds of stimulus material to determine whether there was a global impairment in visual perception or discrimination. Second, we sought to determine whether rhinal cortex lesions would cause abnormally rapid forgetting of postoperatively acquired object discrimination problems.

Parts of this paper have been published previously in abstract form (Thornton and Murray, 1996).

\section{EXPERIMENT 1}

\section{Materials and methods}

\section{Subjects}

Eight experimentally naive rhesus monkeys (Macaca mulatta) weighing between 3.3 and $7.2 \mathrm{~kg}$ at the beginning of testing were used; six of the monkeys were male, and two were female. They were housed in individual cages in rooms with regular $12 \mathrm{hr}$ light/dark cycles and were fed a diet of monkey chow (PMI Feeds Inc., St. Louis, MO) supplemented with fruit. The monkeys were later divided on the basis of their preoperative performance into two groups of four animals each. One group (Rh) received the rhinal cortex lesions, and the other (Con) was kept as an unoperated control group.

\section{Surgery}

Bilateral ablation of the rhinal cortex was performed in a single stage of surgery and was performed under visual control with the aid of an operating microscope. Figure 1 illustrates the extent of the intended lesion. Monkeys were immobilized with ketamine hydrochloride (10 $\mathrm{mg} / \mathrm{kg}$, i.m.) and anesthetized with isoflurane (1.0-2.0\%, to effect); they received an intravenous drip of isotonic fluids, and heart rate, respiration rate, body temperature, and expired $\mathrm{CO}_{2}$ were closely monitored throughout the procedure. After establishment of the aseptic field and skin incision, the zygoma was removed to allow access to the portion of the cranium overlying the ventrolateral surface of the frontal and temporal lobes. Then the temporalis muscle was reflected, and a large bone flap was made; the flap extended rostrally to the orbit, ventrally to the base of the temporal fossa, and caudally to the auditory meatus. Two approaches were used for the ablation. First, a dural flap was cut over the frontal and anterior part of the temporal lobes. Using a supraorbital approach, we gently retracted the frontal lobe from the orbit with a brain spoon, and the anterior part of the rhinal cortex was removed with a small-gauge sucker. This part of the lesion extended along the anterior face of the temporal pole from the lateral fissure to the floor of the temporal fossa and included the cortex lining the banks of the rhinal sulcus as well as $\sim 2 \mathrm{~mm}$ of cortex both medial and lateral to the sulcus. After this part of the removal was completed, the dura was sewn over the frontal lobe, and then an additional dural flap was cut over the lateral part of the temporal lobe. A subtemporal approach was used for ablation of 
Table 1. Rhinal cortex damage

\begin{tabular}{|c|c|c|c|c|c|c|c|c|c|c|c|c|}
\hline \multirow[b]{2}{*}{ Case } & \multicolumn{4}{|c|}{ PRh damage } & \multicolumn{4}{|c|}{ ERh damage } & \multicolumn{4}{|c|}{ Total Rh damage } \\
\hline & $L \%$ & $R \%$ & $\bar{X} \%$ & $W \%$ & $L \%$ & $R \%$ & $\bar{X} \%$ & $W \%$ & $L \%$ & $R \%$ & $\bar{X} \%$ & $W \%$ \\
\hline Rh-1 & 100 & 84 & 92 & 84 & 71 & 64 & 68 & 46 & 86 & 75 & 80 & 64 \\
\hline $\mathrm{Rh}-2$ & 100 & 99 & 99 & 99 & 91 & 77 & 84 & 70 & 96 & 89 & 92 & 85 \\
\hline Rh-3 & 100 & 100 & 100 & 100 & 79 & 79 & 79 & 62 & 90 & 90 & 90 & 81 \\
\hline $\mathrm{Rh}-4$ & 96 & 73 & 85 & 71 & 77 & 63 & 70 & 48 & 87 & 68 & 78 & 60 \\
\hline $\bar{X}$ & 99 & 89 & 94 & 88 & 80 & 71 & 75 & 57 & 90 & 80 & 85 & 72 \\
\hline
\end{tabular}

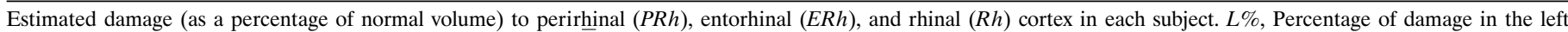

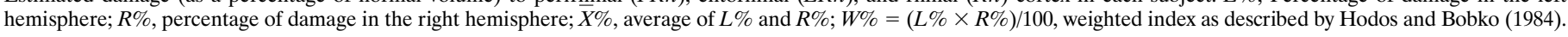

the caudal half of the rhinal cortex, with the monkey's head tilted at an angle of $120^{\circ}$ from the vertical. Mannitol was administered at this time (30\%; $30 \mathrm{ml}$, i.v., over $30 \mathrm{~min})$ to reduce brain volume and increase accessibility of the ventromedial cortex, which was retracted from the base of the temporal fossa. The lesion was continued caudally from the first ablation, along the banks of the rhinal sulcus, to include $\sim 2 \mathrm{~mm}$ of cortex lateral to the sulcus. In addition, the lesion was extended more medially in the posterior region of the sulcus to include all of the entorhinal cortex. After the removal was completed, the dura was sewn, the bone flap was replaced, and the wound was closed in anatomical layers with Vicryl sutures. Dexamethasone sodium phosphate $(0.4 \mathrm{mg} / \mathrm{kg}$, i.m.) and an antibiotic (Di-Trim, $0.1 \mathrm{ml} / \mathrm{kg}, 24 \% \mathrm{w} / \mathrm{v}$ solution, i.m.; Syntex Animal Health Inc., West Des Moines, IA) were administered for $1 \mathrm{~d}$ before surgery and for 1 week after surgery to reduce swelling and to prevent infection, respectively. Monkeys also received acetaminophen $(40 \mathrm{mg})$ for $3 \mathrm{~d}$ after surgery as an analgesic.

\section{Histology}

At the end of the experiment, the monkeys in the operated group were given a lethal dose of barbiturates and perfused intracardially with a saline solution $(0.9 \%)$ followed by $10 \%$ buffered formalin. The brains were removed, photographed, frozen, and cut at $50 \mu \mathrm{m}$ in the coronal plane on a freezing microtome. Every fifth section was mounted on a gelatin-coated slide, defatted, stained with thionin, and coverslipped.

The extent of the lesion was plotted onto standard sections of a rhesus monkey brain using a stereomicroscope, and the volume of the lesion was calculated using a digitizer (see Meunier et al., 1993). The extent of damage to the rhinal cortex in the operated monkeys is shown in Table 1. The damage averaged $85 \%$ (range, $78-92 \%$ ) of the total extent of the rhinal cortex. This included an average of $94 \%$ (range, $85-100 \%$ ) of the perirhinal cortex and $75 \%$ (range, $68-84 \%$ ) of the entorhinal cortex.

Reconstructions of the lesion and representative coronal sections through the lesion from each monkey with a rhinal cortex ablation are illustrated in Figures 2-5; in addition, photomicrographs are shown in Figures 6 and 7. In all cases, the lesion encroached slightly on the most rostral portion of the piriform cortex and, more posteriorly, into area TE; very slight encroachment into area TF occurred in cases $\mathrm{Rh}-1, \mathrm{Rh}-2$, and $\mathrm{Rh}-4$. In addition, every case showed some sparing of the entorhinal cortex; the most consistent sparing occurred in the most medial portion of the entorhinal cortex below the posterior half of the amygdala. Cases Rh- 1 and Rh-4 also showed modest sparing of the perirhinal cortex on the right. Otherwise, the lesions were as intended.

\section{Test apparatus and materials}

All behavioral testing was conducted in a Wisconsin General Testing Apparatus (WGTA) located in a dark room equipped with a white-noise generator. The test compartment of the WGTA was illuminated with two 60-watt incandescent light bulbs. The test tray contained two food wells $38 \mathrm{~mm}$ in diameter and $275 \mathrm{~mm}$ apart center to center. Food rewards, which were determined according to each individual monkey's preference at the beginning of training, consisted of either one banana pellet (300 mg; Noyes, Lancaster, NH) or one-half of a peanut. During intertrial intervals $(20 \mathrm{sec})$, an opaque screen separated the animal from the stimulus tray and the experimenter. During choice tests, the experimenter could view the monkeys through a one-way viewing screen. Test materials consisted of several identical gray plaques used in acclimating the animals to displace objects for food reward and 240 "junk" objects that varied widely in size, shape, and color and served as visual discriminanda, plus three additional objects used only in preliminary training.

\section{Preoperative testing procedures}

Preliminary training. Monkeys were trained by successive approximation to displace gray plaques that completely covered the food wells. They were then trained to displace three different objects, one at a time, placed in random order over the left and right wells on the test tray.

Twenty-four hour concurrent object discrimination. Before surgery, monkeys were trained to criterion on two sets of object discriminations consisting of 60 problems each. One set of problems was learned $\sim 16$ weeks $(\mathrm{Rh}$ group, mean $=15.9$; Con group, mean $=15.4)$ before surgery or rest, and the other was learned $\sim 1$ week ( $\mathrm{Rh}$ group, mean $=1.3$; Con group, mean $=1.7$ ) before surgery or rest. On each trial, two different objects, one arbitrarily designated positive (i.e., covering a baited well) and the other negative (i.e., covering an unbaited well), were presented for choice, and the monkey was allowed to displace one item. If the monkey displaced the positive object of the pair, then it could obtain the food reward hidden underneath. After a $20 \mathrm{sec}$ interval, the next pair of objects was presented, and so on, until the 60 pairs comprising a test session had been used. The order of presentation of pairs was the same for each monkey both within and across sessions, and a noncorrection procedure was used; the left-right position of the correct object followed a pseudorandom order. Training proceeded at the rate of 5 or $6 \mathrm{~d}$ per week. Criterion was set at $90 \%$ correct responses over five consecutive sessions (i.e., 270 correct choices out of 300). After the monkeys had attained criterion, two groups balanced on the basis of their preoperative learning scores were formed.

\section{Postoperative testing procedures}

Retention of preoperatively learned object discriminations. After a postoperative recovery period of 2 weeks or an equivalent period of rest, monkeys were reacclimated to the testing procedure in one session ( 30 trials) in which they were required to displace one of two identical gray plaques covering the food wells on each trial. We then measured retention in two different ways. First, beginning the following day, retention of the preoperatively learned object discriminations was assessed by administering 120 trials, one per problem. The single, critical trial for each of the 120 pairs was presented in mixed order on one of 2 consecutive days (60 trials/d). Half of the problems in each set were administered each day. Second, after an additional rest period of 2 weeks, retention was assessed by measuring the extent of savings to relearn each set of 60 object discriminations. Monkeys were retrained on each set of problems in the same manner as used in original learning and to the same criterion. To control for order effects, we retrained half of the animals in each group to criterion on the first set followed by the second set, whereas the other half were retrained on the two sets in the reverse order. A percent savings score was calculated for each monkey and for each set according to the formula $[(L-R) /(L+R)] \times 100$, where $L$ and $R$ equal the total number of errors accumulated during preoperative learning and postoperative retention, respectively.

\section{Results}

\section{Preoperative learning}

Number of sessions to criterion. Monkeys learned the discriminations from the two sets in an average of 9 sessions (Fig. 8). The number of sessions to criterion during acquisition of each set of 60 object discrimination problems was compared using a $2 \times 2$ repeated-measures ANOVA, with the training period [16 or 1 week(s)] as the repeated within-subjects factor and with lesion 


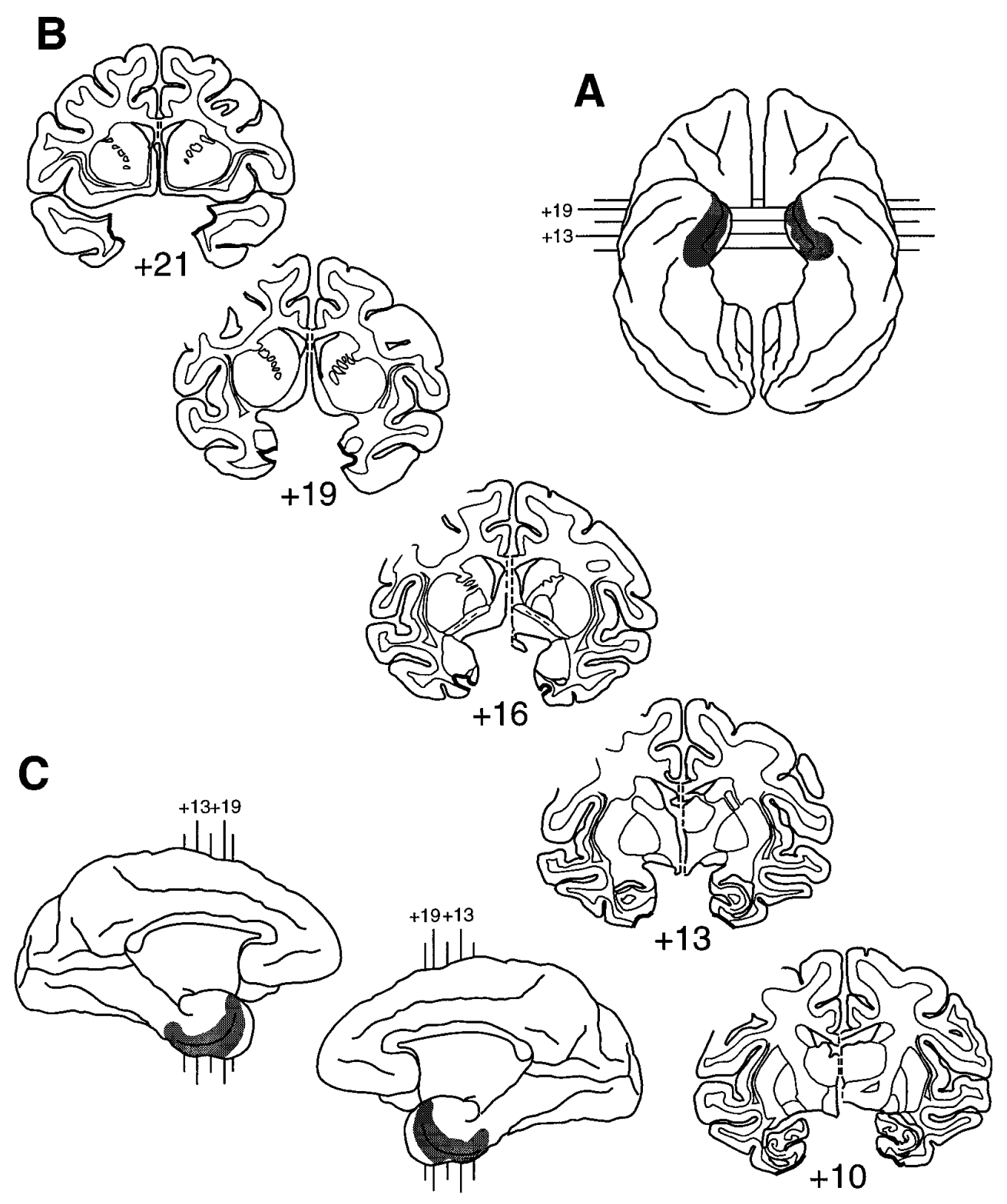

Figure 2. Extent of the rhinal cortex lesion in $\mathrm{Rh}-1 . A$, Ventral view (reversed to aid in matching to coronal sections). $B$, Coronal sections; thick black lines indicate the line along which the lesion was made. $C$, Medial aspect of both hemispheres. In both $A$ and $C$, shaded areas indicate the extent of the lesion reconstructed from individual sections. The numerals indicate the distance in millimeters from the interaural plane. Compare and contrast with Figure 1. group (rhinal cortex lesion or unoperated control) as the between-subjects factor. As expected, there was no significant interaction between training period and lesion group $(F=1.68$; df $=1,6 ; p>0.10)$, no significant main effect of training period $(F=3.429 ; \mathrm{df}=1,6 ; p>0.10)$, and no significant main effect of lesion group $(F=0.239$; df $=1,6 ; p>0.10)$.

Number of errors to criterion. A similar analysis was performed for errors to criterion. Again, there was no significant interaction between training period and lesion group $(F=0.983$; df $=1,6$; $p>0.10)$ and no significant main effect of lesion group $(F=$ $0.084 ; \mathrm{df}=1,6 ; p>0.10)$. There was, however, a significant main effect of training period $(F=23.933$; df $=1,6 ; p<0.004)$, indicating that the second set was learned with fewer errors than was the first.

\section{Postoperative retention}

Critical trials. When retention was assessed by examining the choices of the monkeys on a single, critical trial per discrimination problem (Fig. 9), monkeys with rhinal cortex removals scored an average of $68 \%$ correct (remote, $65 \%$; recent, $71 \%$ ), whereas controls scored 91\% (remote, 88\%; recent, 94\%). A $2 \times 2$ repeated-measures ANOVA revealed no significant interaction between training period and lesion group $(F=0.019$; df $=1,6$; $p>0.05)$, but there was a significant main effect of lesion group $(F=25.335 ; \mathrm{df}=1,6 ; p<0.003)$ and a significant main effect of training period $(F=7.414$; df $=1,6 ; p<0.04)$. Thus, monkeys with ablations of the rhinal cortex showed poor retention relative to controls of the problems learned both 1 and 16 weeks before surgery. Furthermore, the monkeys in both groups exhibited significantly better retention of the more recently learned set. There was no evidence of a differential effect of the lesion on the retention of material from the two sets.

Analysis of the scores on the $2 \mathrm{~d}$ of critical trials, using a $2 \times$ 2 repeated-measures ANOVA, showed no significant main effect of day of testing $(F=0.006 ; \mathrm{df}=1,6 ; p>0.05)$ and no significant interaction of day $\times$ lesion group $(F=1.794$; df $=1,6 ; p>0.05)$.

Savings to relearn. As was the case for critical trials, savings to relearn the discrimination problems revealed that monkeys with rhinal cortex removals showed poor retention of the preopera- 

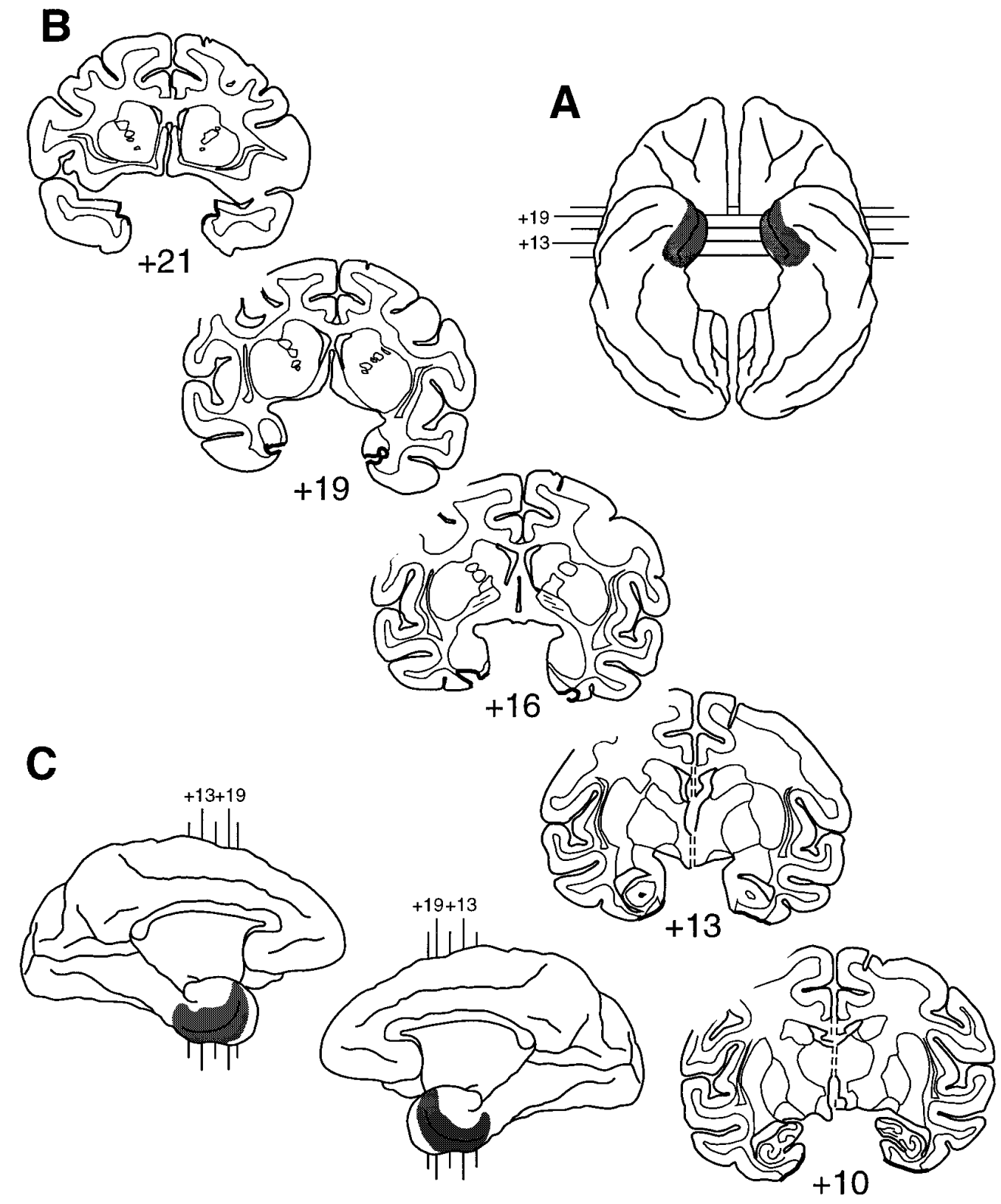

Figure 3. Extent of the rhinal cortex lesion in $\mathrm{Rh}-2 . A$, Ventral view (reversed to aid in matching to coronal sections). $B$, Coronal sections; thick black lines indicate the line along which the lesion was made. $C$, Medial aspect of both hemispheres. In both $A$ and $C$, shaded areas indicate the extent of the lesion reconstructed from individual sections. The numerals indicate the distance in millimeters from the interaural plane. Compare and contrast with Figure 1.

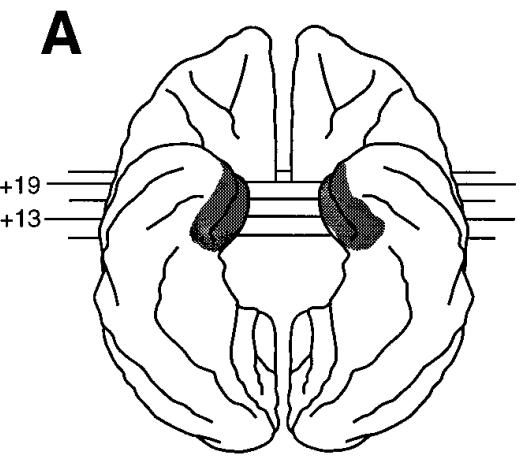

tively learned problems relative to the controls (57 vs $84 \%$; Fig. 10). Unlike the critical trials measure, however, the savings measure provided no evidence of better retention of the more recently learned set. A $2 \times 2$ repeated-measures ANOVA was performed on the percent savings in the total number of errors during relearning, including those errors scored during the 5 criterion days. There was no significant interaction between training period and lesion group $(F=0.972 ; \mathrm{df}=1,6 ; p>0.05)$. There was also no significant main effect of training period $(F=4.443$; $\mathrm{df}=1,6 ; p>0.05)$. There was a significant main effect of lesion group $(F=9.154 ; \mathrm{df}=1,6 ; p<0.03)$, the monkeys with rhinal cortex lesions exhibiting a significantly lower percentage of savings in postoperative relearning compared with the controls.

\section{Discussion}

Monkeys with lesions of the rhinal cortex were significantly impaired on two measures of postoperative retention of the preoperatively learned object discrimination problems: critical trials and savings to relearn. Both measures indicated that the retro- grade amnesia exhibited by the operated monkeys was not temporally graded. Furthermore, a consideration of the scores obtained on the critical trials suggests that all monkeys showed slightly better retention of problems in the recent relative to the remote set. Thus, the scores of the operated monkeys on the two sets of problems were in a direction opposite to that expected if the rhinal cortex played a temporally limited role in information storage. There is no reason to think that the preoperative rates of learning of the two sets interacted with the lesion in some way to hide a temporal gradient. First, there was no difference in the number of sessions required to learn the two sets. Second, although, on average, monkeys learned the second (recent) set of problems more quickly than they did the first (remote), the single monkey in the operated group ( $\mathrm{Rh}-2)$ that was slower to learn the second set relative to the first showed the same pattern of better postoperative retention of recent versus remote problems.

Because the monkeys with rhinal cortex removals were subsequently able to learn new discrimination problems of the same 

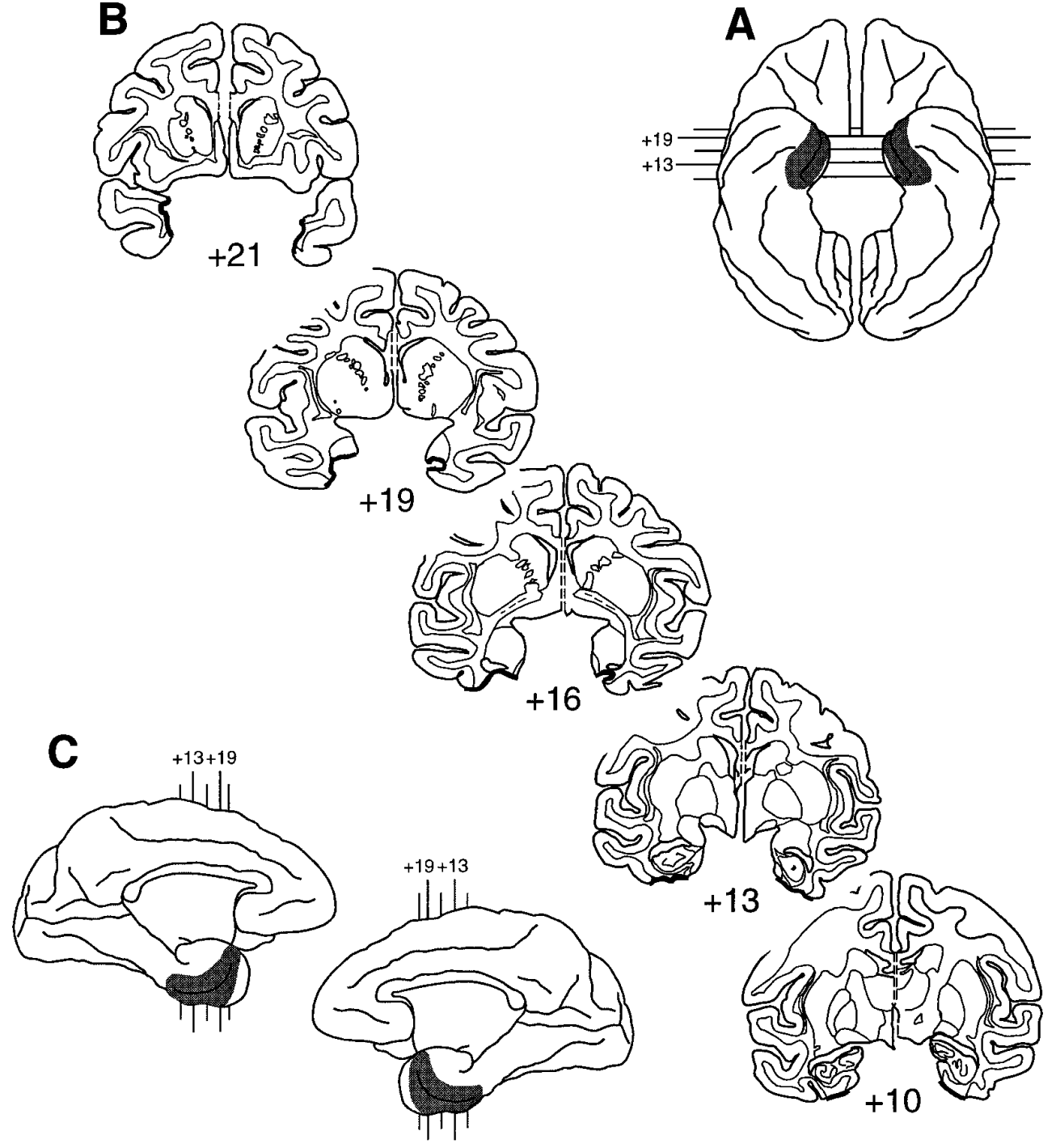

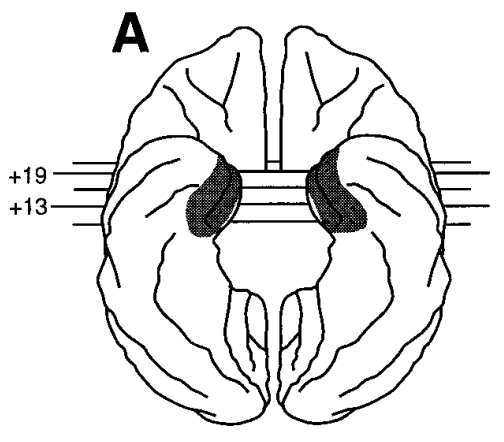

Figure 4. Extent of the rhinal cortex lesion in Rh-3. $A$, Ventral view (reversed to aid in matching to coronal sections). $B$, Coronal sections; thick black lines indicate the line along which the lesion was made. $C$, Medial aspect of both hemispheres. In both $A$ and $C$, shaded areas indicate the extent of the lesion reconstructed from individual sections. The numerals indicate the distance in millimeters from the interaural plane. Compare and contrast with Figure 1. type at the same rate as did controls (see Experiment 2), we can rule out the possibility that the impairment was caused by a gross alteration in perception or discrimination abilities per se. In addition, the impairments are unlikely to reflect nonspecific, short-term effects of the surgical procedure. There are many examples in the literature of intact retention of preoperatively learned visual discriminations after cortical excisions or transections performed under general anesthesia (Chow and Orbach, 1957; Chow and Survis, 1958; Orbach and Fantz, 1958; Laursen, 1982; Gaffan, 1994b). Alternatively, there might have been a transient disruption of retrieval or a short-term deficit in perceptual ability. These possibilities seem unlikely because monkeys with similar lesions demonstrated impaired stimulus recognition with no detectable recovery of function after many months of testing (Meunier et al., 1993; Eacott et al., 1994). Instead, the impairment seems to reflect a true loss of information.

The finding that retention of preoperatively learned problems was significantly disrupted by rhinal cortex lesions confirms earlier reports that also examined retention of object discrimination problems after lesions of the rhinal cortex (Gaffan and Murray, 1992) or the perirhinal cortex (Buckley and Gaffan, 1997). The current results extend those findings by showing that this effect of rhinal cortex removals holds for information stored up to 16 weeks before surgery, a period of time approximately twice as long as had been thought to be required for "hippocampal" consolidation in macaque monkeys, a point considered in more detail in the final Discussion. Thus, it seems that, in intact animals, the rhinal cortex contributes to the long-term retention of these types of learned visual object discriminations.

The current findings differ from those recently obtained in rats. Wiig et al. (1996) reported a temporally graded retrograde amnesia for learned object discriminations after lesions of perirhinal cortex, and Cho et al. (1993, 1995) and Cho and Kesner (1996) reported temporally graded impairments in spatial memory after lesions of entorhinal cortex. The discrepant results could be caused by differences in the lesions, tasks, or species. However, in the study by Wiig et al. (1996), the impairment observed on object discrimination problems learned 1,2, 4, and 8 weeks before surgery was absent only for a single problem learned 6 weeks before surgery, raising questions about the reliability of the temporal gradient in that study.

\section{EXPERIMENT 2}

As indicated above, one goal of Experiment 2 was to evaluate the visual perceptual and discriminative abilities of the operated monkeys. In addition, although acquisition of concurrent object 
B

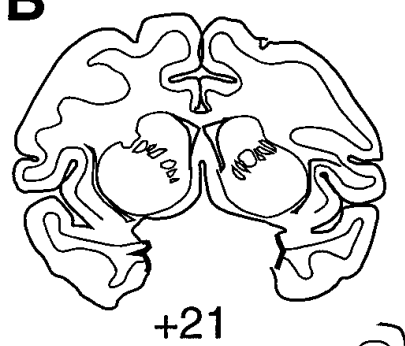

C

Figure 5. Extent of the rhinal cortex lesion in $\mathrm{Rh}-4 . A$, Ventral view (reversed to aid in matching to coronal sections). $B$, Coronal sections; thick black lines indicate the line along which the lesion was made. $C$, Medial aspect of both hemispheres. In both $A$ and $C$, shaded areas indicate the extent of the lesion reconstructed from individual sections. The numerals indicate the distance in millipare and contrast with Figure 1. meters from the interaural plane. Com-
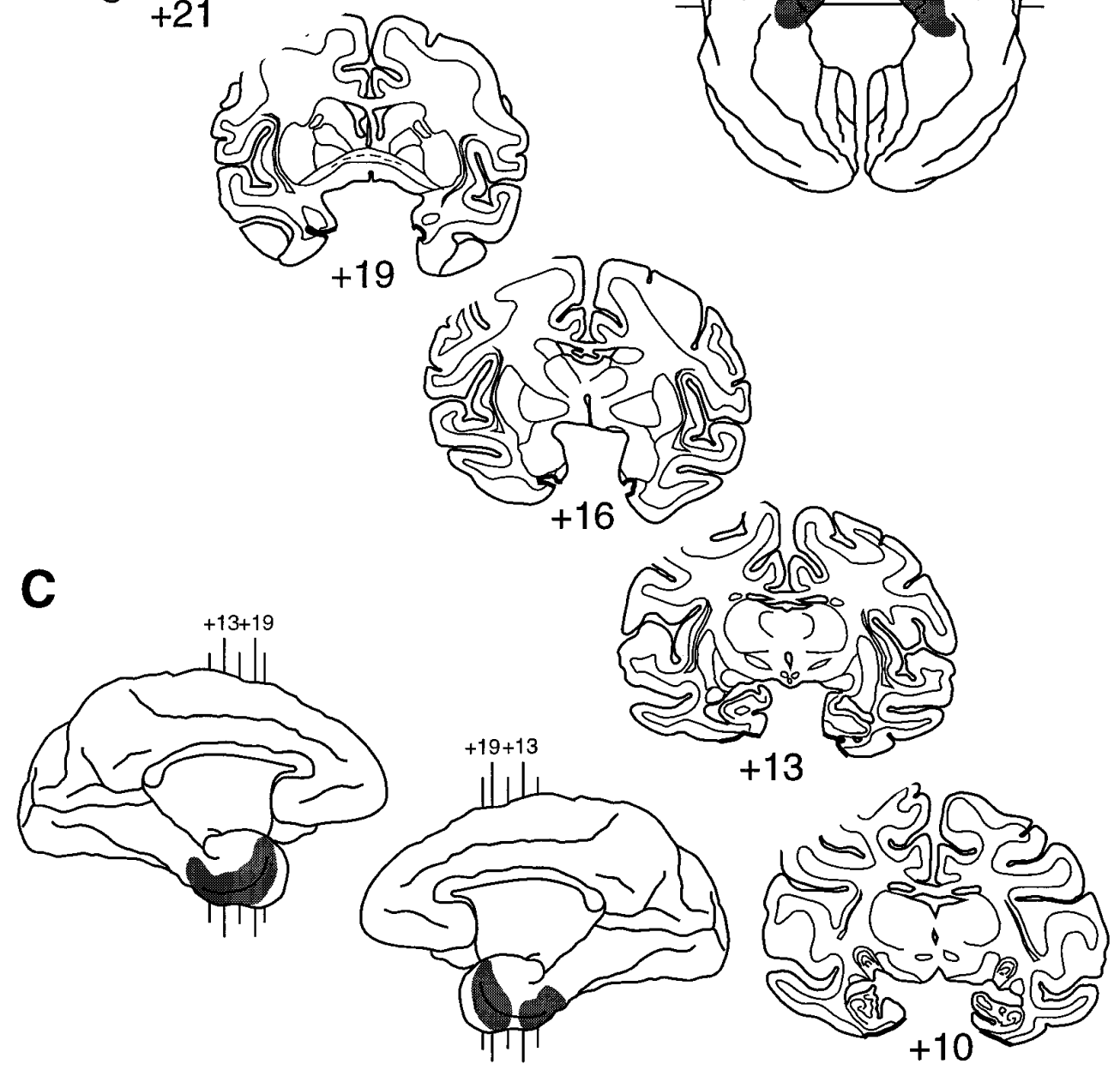

to relearn. Finally, in an attempt to increase the sensitivity of the retention test, we presented a third set of discrimination problems. The monkeys were trained using short intertrial intervals, as before, but now retention was assessed using errors to learn a reversal of each of the original problems.

\section{Materials and Methods}

\section{Subjects}

The same monkeys were used as described in Experiment 1.

\section{Test apparatus and materials}

All behavioral testing was conducted using the same WGTA and the same test tray described in Experiment 1; 60 novel objects were used as visual discriminanda.

\section{Postoperative testing procedures}

Acquisition and retention of object discriminations: $24 \mathrm{hr}$ intertrial intervals. Each monkey was trained on a new set of discrimination problems consisting of 10 pairs. The task was administered in the same way as described for the preoperatively learned pairs in Experiment 1, except different ways, with short ( $\sim 20 \mathrm{sec})$ and long $(\sim 24 \mathrm{hr})$ intertrial intervals. In each case, retention was assessed by measuring errors

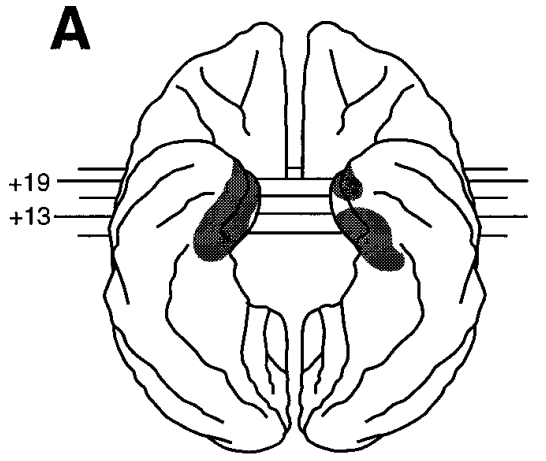

learning, has been theorized to be more dependent on mec temporal lobe structures than the learning of discrimination problems administered with long, $24 \mathrm{hr}$ intervals (Squire and ZolaMorgan, 1983; Phillips et al., 1988). Consequently, we examined retention of visual discrimination problems presented in two 

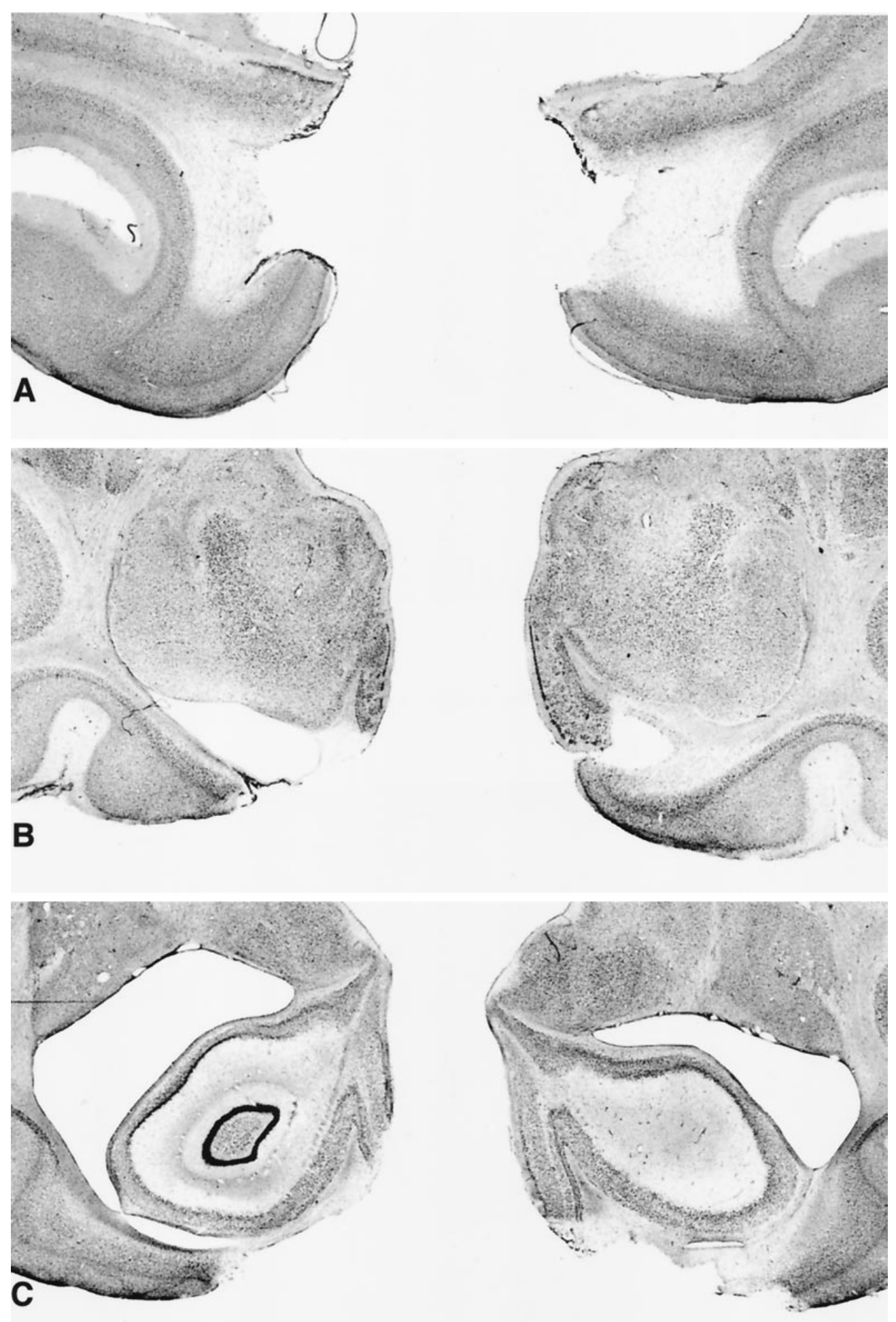

Figure 6. Photomicrographs of Nisslstained coronal sections from a monkey with a bilateral rhinal cortex lesion (Rh2). Sections $A, B$, and $C$ are approximately $+20,+16$, and $+13 \mathrm{~mm}$ from the interaural plane, respectively. Compare and contrast with Figure 3. that there were 10 trials per session instead of 60 . Training was continued until each monkey had attained the criterion of an average of $90 \%$ correct responses over 5 consecutive days. Three weeks after acquisition of the 10 problems, retention was assessed. Monkeys were retrained on the 10 object discrimination problems in the same manner used in original learning and to the same criterion.

Acquisition and retention of object discriminations: massed trials. Animals were trained on 10 new object discrimination problems. The same order of problems was used for each monkey. On a given day, each of two object discrimination problems was trained serially to a criterion of 9 out of 10 consecutive correct trials. This procedure was repeated for a total of 5 consecutive days, providing a total of 10 problems. Three weeks after each problem had been learned, retention was assessed by presenting the 10 object discrimination problems for relearning in the same way they had been presented during the acquisition phase of the experiment.

Acquisition and retention of object discriminations: massed trials with reversals. The monkeys were presented with 10 new object discrimination problems, two per day, until each object discrimination was learned to a criterion of 9 out of 10 consecutive correct trials. The same order of problems was used for each monkey. Three weeks after each of the problems had been learned, retention was assessed by presenting the 

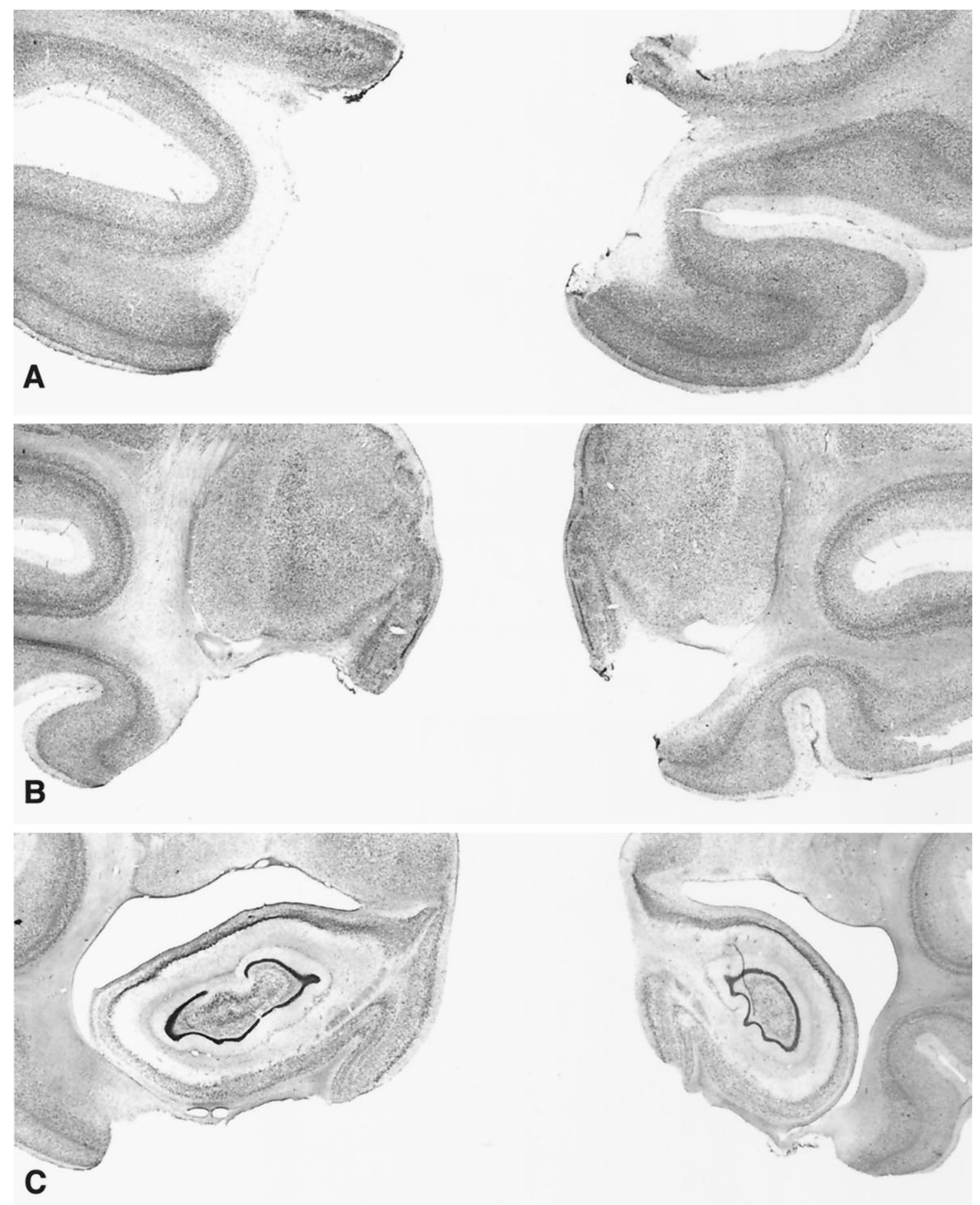

Figure 7. Photomicrographs of Nissl-stained coronal sections from a monkey with a bilateral rhinal cortex lesion (Rh-3). Sections $A, B$, and $C$ are approximately $+20,+16$, and $+13 \mathrm{~mm}$ from the interaural plane, respectively. Compare and contrast with Figure 4 .

same 10 pairs in the same order and to the same criterion used before, but with the valence of each object reversed.

\section{Results}

\section{Acquisition and retention of object discriminations: $24 \mathrm{hr}$} intertrial intervals

The two groups showed equally rapid acquisition of the discrimination problems, scoring a mean of 23 total errors in initial learning. Three weeks later, the two groups likewise showed equally good retention, scoring a mean of 6 total errors in relearning (Fig. 11). A $2 \times 2$ repeated-measures ANOVA showed no significant interaction between lesion group and training period $(F=0.865 ; \mathrm{df}=1,6 ; p>0.05)$ and no significant main effect of lesion group $(F=0.081$; df $=1,6 ; p>$ $0.05)$. There was a significant main effect of training period $(F=23.758 ; \mathrm{df}=1,6 ; p<0.004)$, reflecting the high level of retention in both groups. 


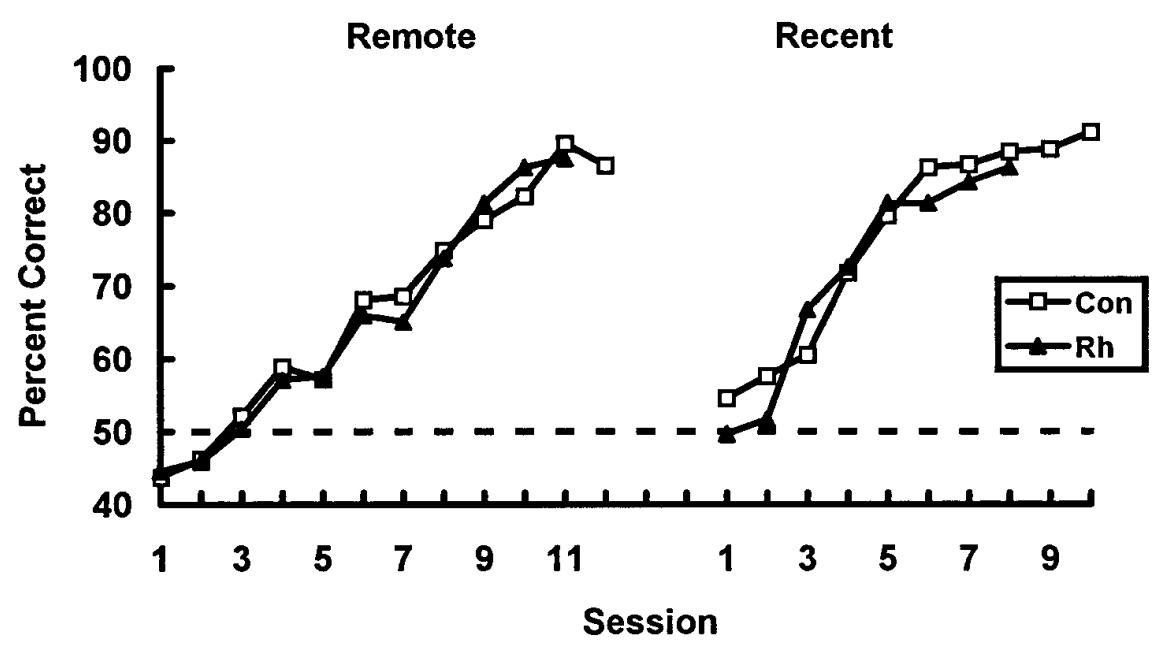

Figure 8. Mean rates of original (preoperative) learning of each set of object discrimination problems. The dashed line denotes chance performance. $C o n$, Unoperated controls; $R h$, monkeys assigned to receive bilateral ablations of the rhinal cortex. Remote, Object discrimination problems learned 16 weeks before surgery or rest; Recent, object discrimination problems learned 1 week before surgery or rest.

\section{Acquisition and retention of object discriminations: massed trials}

As was the case for the problems learned with $24 \mathrm{hr}$ intertrial intervals, both groups showed equally efficient acquisition and retention of the rapidly learned discrimination problems. Again, there was no significant interaction between lesion group and training period $(F=0.016 ; \mathrm{df}=1,6 ; p>0.05)$, no significant main effect of lesion $(F=0.758 ; \mathrm{df}=1,6 ; p>0.05)$, but a significant main effect of training period $(F=26.342 ; \mathrm{df}=1,6$; $p<0.003$ ), reflecting good retention in both groups (Fig. 12). A comparison between the groups of the number of correct responses on the first trial of each object discrimination pair during second testing, a pure measure of retention taken before any relearning occurred, also failed to reveal a significant difference $(t=-0.739 ; p>0.05)$.

\section{Acquisition and retention of object discriminations: massed} trials with reversals

Once again there was no significant interaction between lesion group and training period $(F=2.207 ; \mathrm{df}=1,6 ; p>0.05)$, no

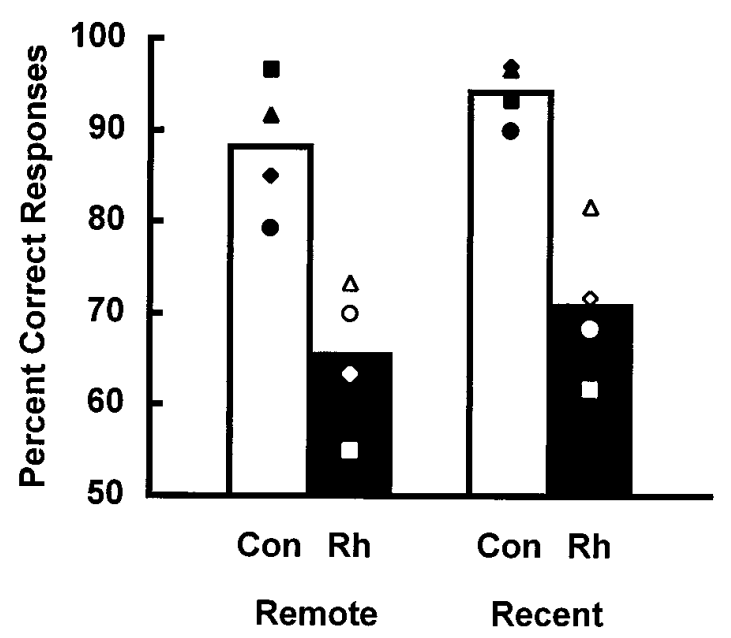

Figure 9. Mean percent correct responses on critical trials as a function of training period. Con, Unoperated controls; $R h$, monkeys with bilateral ablations of the rhinal cortex; Remote, object discrimination problems learned 16 weeks before surgery or rest; and Recent, object discrimination problems learned 1 week before surgery or rest. Open triangle, Rh1; open diamond, $\mathrm{Rh} 2$; open circle, Rh3; open square, Rh4; filled triangle, Con1; filled diamond, Con2; filled circle, Con3; and filled square, Con4. significant main effect of lesion group $(F=3.364 ; \mathrm{df}=1,6 ; p>$ $0.05)$, but a significant main effect of training period $(F=22.828$; $\mathrm{df}=1,6 ; p<0.004$ ), this time reflecting negative transfer (Fig. 13). A group comparison for number of correct responses on the first trial of each object discrimination pair during reversal learning also failed to reveal a significant difference $(t=0.333 ; p>0.05)$.

\section{Discussion}

Monkeys with ablations of the rhinal cortex were unimpaired in the acquisition and retention of object discriminations when the learning occurred postoperatively. As indicated in the introduction to Experiment 2, it has been reported previously that acqui-

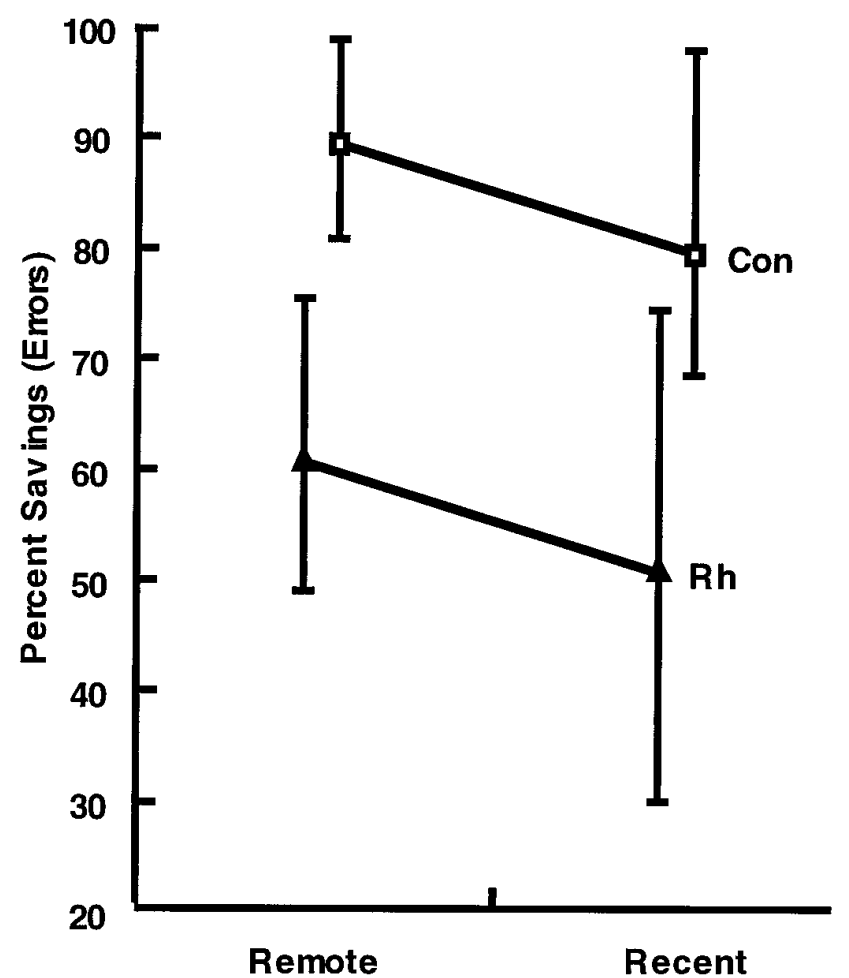

Figure 10. Average percent savings in the total number of incorrect responses during relearning of each set. Vertical bars represent the range of scores in each group. Con, Unoperated controls; $R h$, monkeys with bilateral ablations of the rhinal cortex; Remote, object discrimination problems learned 16 weeks before surgery or rest; and Recent, object discrimination problems learned 1 week before surgery or rest. 


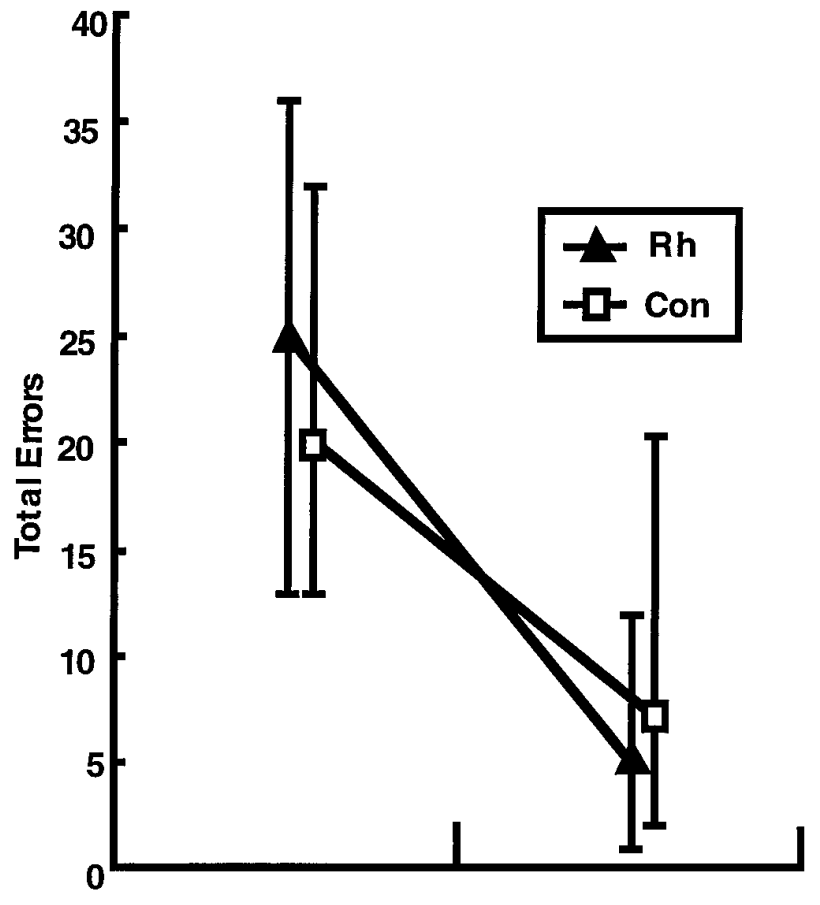

\section{Acquisition}

Retention

Figure 11. Mean number of errors for each group during acquisition and retention of 10 object discrimination problems presented at $24 \mathrm{hr}$ intertrial intervals. Vertical bars represent the range of scores in each group. Con, Unoperated controls; $R h$, monkeys with bilateral ablations of the rhinal cortex.

sition of object discrimination problems is normal after rhinal cortex lesions (Gaffan and Murray, 1992; Eacott et al., 1994; cf. Buckley and Gaffan, 1997), and our results confirm that finding. A new finding, however, is the good retention of the postoperatively acquired material. The mode of presentation of the discrimination problems had no effect on learning or retention; the operated monkeys continued to perform at a level comparable with the controls regardless of whether the visual discriminations were presented concurrently with $24 \mathrm{hr}$ intertrial intervals or serially with massed trials and short intertrial intervals. Because relearning to criterion may be somewhat insensitive because of ceiling effects, we also examined reversal learning. Even under these conditions, which arguably constitute a more sensitive measure, monkeys with rhinal cortex removals performed no differently from controls.

Although no studies have examined the role of the rhinal cortex in postoperative acquisition and retention in rats, some have examined related issues. Vnek and colleagues found that rats with entorhinal-hippocampal disconnection (Vnek et al., 1995) or aspiration lesions of the dorsal hippocampus (Vnek and Rothblat, 1996) showed normal acquisition but impaired retention of visual object discrimination problems learned postoperatively. A similar pattern of intact acquisition but impaired retention on other discrimination tasks was found after lesions of entorhinal cortex (Staubli et al., 1984, 1986; Levisohn and Isacson, 1991). Also, rats with perirhinal cortex lesions show normal acquisition of an object discrimination problem but impaired learning and retention of a discrimination reversal (Wiig et al., 1996). In sum, in contrast to the present study, the foregoing studies in rats dem-

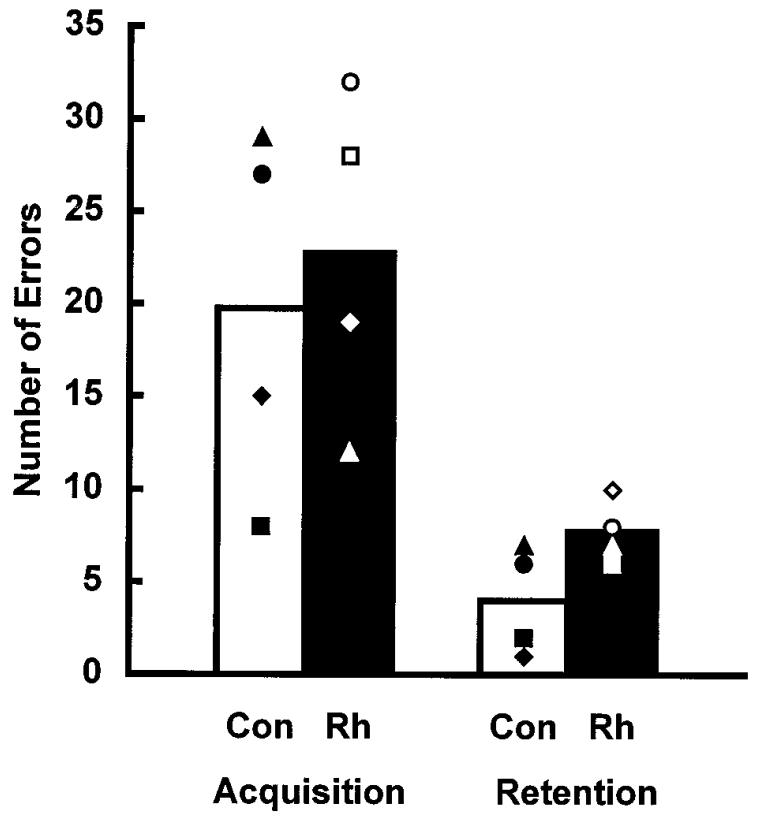

Figure 12. Average number of errors (including the criterion run) for each group during acquisition and retention of 10 object discrimination problems presented with massed trials. Con, Unoperated controls; $R h$, monkeys with bilateral ablations of the rhinal cortex. Open triangle, Rh1; open diamond, Rh2; open circle, Rh3; open square, Rh4; filled triangle, Con1; filled diamond, Con2; filled circle, Con3; and filled square, Con4.

onstrate poor retention of postoperatively acquired material after medial temporal lobe damage. As was the case for our findings on retention of preoperatively learned discriminations, the apparent discrepancy regarding retention of postoperatively learned discriminations could be caused by many variables, such as the locus of the lesion, the species studied, or the type of visual discrimination that was used.

It has been suggested that rapidly learned discrimination problems are more sensitive to medial temporal lobe damage than are slowly learned problems (Squire and Zola-Morgan, 1983). In Experiment 2, there was no effect of the rhinal cortex lesions on either acquisition or retention of visual discrimination problems, although all the problems were learned quite rapidly (mean trials to criterion: set $1,5.63$; set $2,1.91$; and set $3,2.45$ ). Thus, these data argue against the idea that rapid learning is especially susceptible to medial temporal lobe damage.

\section{DISCUSSION}

\section{Implications for consolidation theories of medial temporal lobe function}

Zola-Morgan and Squire (1990) found evidence of temporally graded retrograde amnesia in monkeys after removals of the hippocampal formation, entorhinal cortex, and parahippocampal cortex, in that retention of discrimination problems learned 8-16 weeks before surgery was as good as that of controls, whereas retention of problems learned closer to the time of surgery was poor relative to that of controls. In our study, there was no evidence of memory consolidation outside the rhinal cortex in a time period that was approximately twice as long, indicative of a flat, temporally extensive retrograde amnesia after damage to the rhinal cortex. These findings can be reconciled with those of Zola-Morgan and Squire in two main ways: (1) the rhinal cortex but not the hippocampus acts as a permanent site of storage of 


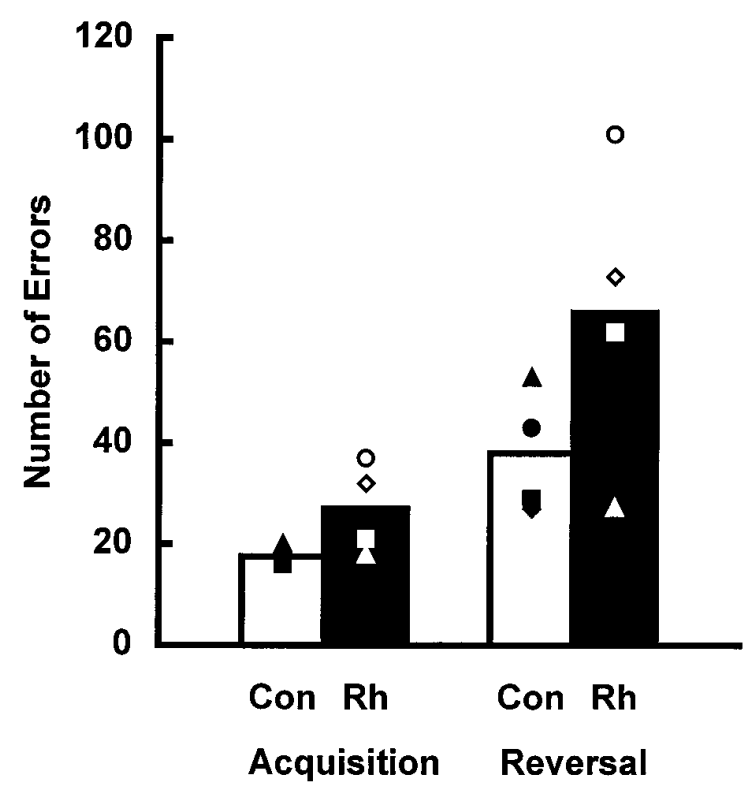

Figure 13. Average number of errors (including the criterion run) for each group during acquisition and retention (reversals) of 10 object discrimination problems presented with massed trials. Con, Unoperated controls; $R h$, monkeys with bilateral ablations of the rhinal cortex. Open triangle, Rh1; open diamond, $\mathrm{Rh} 2 ;$ open circle, $\mathrm{Rh} 3 ;$ open square, $\mathrm{Rh} 4$; filled triangle, $\mathrm{Con} 1 ;$ filled diamond, Con2; filled circle, Con3; and filled square, Con4.

object information, or (2) any consolidation process mediated by the rhinal cortex requires more passage of time than that mediated by the hippocampus. Either way, the notion of a single consolidation process mediated by medial temporal lobe structures (Alvarez and Squire, 1994; Squire and Alvarez, 1995) is in need of revision. There are at least two issues that need to be addressed in future prospective studies of retrograde amnesia. First, the effects of medial temporal lobe lesions on retention should be evaluated separately for each subdivision (e.g., hippocampus, amygdala, entorhinal cortex, perirhinal cortex, and parahippocampal cortex). Second, different kinds of memory (e.g., spatial, object, and motor) should be examined. Other investigators (Nadel and Moscovitch, 1997), after reviewing both the clinical and experimental literature, have likewise suggested that the "standard model" of a single consolidation process is in need of revision.

Salmon et al. (1987) reported that monkeys with large medial temporal lobe lesions had a temporally extensive retrograde amnesia for object discriminations. Although Salmon et al. suggested that their finding of a flat retrograde amnesia might be caused by a lack of forgetting in the normal animals, it now seems that forgetting is not a requirement for detection of temporally graded retrograde amnesia (Kim and Fanselow, 1992; Kim et al., 1995). Interestingly, the monkeys studied by Salmon et al. sustained combined aspiration and radio frequency lesions of the hippocampal formation and amygdala, respectively, removals that included the underlying entorhinal and parahippocampal cortex and could be expected to involve projection systems of the perirhinal cortex (Goulet et al., 1998). Thus, it is possible that the finding of a temporally extensive retrograde amnesia in that study, as in the present study, is because of damage (both direct and indirect) to the rhinal cortex. It should be noted that the perirhinal cortex is much more critical for stimulus memory than is the entorhinal cortex (Meunier et al., 1993; Leonard et al., 1995). Consequently, any effects on retrograde memory in our study may well have arisen from damage to the perirhinal rather than to the entorhinal cortex, a conclusion supported by the findings of Buckley and Gaffan (1997), who found poor retention of preoperatively learned object discrimination problems in their monkeys with lesions limited to the perirhinal cortex. If so, retrograde memory loss can be ascribed to damage to the perirhinal rather than to the entorhinal cortex in the present study and that by Salmon et al. and, by extension, to damage to the hippocampal formation and/or parahippocampal cortex rather than to the entorhinal cortex in the study by ZolaMorgan and Squire (1990).

Gaffan (1993) also found temporally extensive retrograde amnesia for complex scene discriminations in monkeys with fornix transections. In his study, the basic finding obtained with fornix transection, a significant impairment in retention of preoperatively learned discriminations with no temporal gradient (i.e., no differential effect of the lesion on recently vs remotely learned problems), mirrors our own with rhinal cortex ablation. This opens the possibility that the fornix, a fiber bundle connecting the medial temporal lobes with the diencephalon and containing axons arising from neurons in the rhinal cortex (Aggleton and Mishkin, 1984), participates in retention of discrimination problems by virtue of its relationship with the rhinal cortex. Consistent with this notion, the interaction of the perirhinal cortex and fornix has been found to be essential for the learning of at least some types of material (Gaffan and Parker, 1996).

\section{Neural substrates of stimulus memory}

What is the nature of the impairment that follows rhinal cortex damage? Specifically, why are monkeys impaired on retention of preoperatively learned, but not postoperatively learned, object discriminations? One possibility is that the two large sets (60 pairs) of preoperatively learned object discriminations placed more demands on visual identification mechanisms than did the small sets (10 pairs) of postoperatively learned object discriminations, and our intact postoperative acquisition and retention is an artifact of set size. Eacott et al. (1994) found that damage to the rhinal cortex yields impairments on delayed matching-tosample with large sets but not with small sets of visual discriminanda; accordingly, these authors suggested that increasing the demands placed on object identification mechanisms by increasing the number of stimuli to be discriminated was the crucial factor leading to impairment. Newer findings, however, argue against this possibility. First, Buckley and Gaffan (1997) tested this idea directly by examining the effects of perirhinal cortex lesions on visual discrimination learning as a function of the number of pairs to be discriminated and, separately, the number of foils used. Although their monkeys with perirhinal cortex lesions were marginally impaired in new learning, there was no apparent relationship between set size or number of foils and magnitude of the deficit. Second, our monkeys with rhinal cortex removals, trained later on a new set of 60 object discrimination problems, learned them as fast as the controls (Thornton et al., 1997). Thus, it now seems highly unlikely that the intact postoperative retention observed in Experiment 2 can be explained by the relatively small stimulus sets that were used.

Although it may be tempting to conclude that the normal retention of postoperatively learned problems demonstrates an absence of anterograde amnesia in our monkeys with rhinal cortex removals, especially because there are clinical reports of retrograde amnesia in the absence of anterograde amnesia in humans after anteromedial temporal cortex damage (for review, 
see Markowitsch, 1995), such a conclusion would be premature. Although retention of postoperatively learned material was not disrupted in the present study, retention of some types of postoperatively acquired material is affected by rhinal cortex removals. Notably, monkeys with rhinal cortex removals show rapid forgetting of single objects as measured in delayed matching- and nonmatching-to-sample tasks (Meunier et al., 1993; Eacott et al., 1994). Furthermore, the rhinal cortex plays a critical role in mediating the storage of associations among the different parts of individual objects and the different sensory qualities arising from individual objects (Murray et al., 1993, 1997; Higuchi and Miyashita, 1996). Based on these and other observations, it has been suggested that the rhinal cortex serves as the kernel of a system specialized for storing knowledge about objects, thereby mediating object identification (Murray, 1996; Murray et al., 1997). The most parsimonious explanation of our data, which is admittedly speculative but is nevertheless consistent with our current information regarding the functions of the various medial temporal lobe structures, is that initial, preoperative learning of object discrimination problems proceeds primarily via two main systems for stimulus learning and retention: (1) an object knowledge system centered in the rhinal cortex, which stores, inter alia, evaluative information about objects (Murray, 1996; Liu and Richmond, 1997; Murray et al., 1997), and (2) a procedural system lying at least partly outside the rhinal cortex, which stores adaptive rules for responding (Malamut et al., 1984; ZolaMorgan and Squire, 1984). On removal of the rhinal cortex, the object knowledge system is disrupted, resulting in the observed retrograde memory loss, but the procedural system remains, thereby accounting for the small amount of postoperative savings and the good postoperative learning and retention of new problems. Future studies should investigate the potential interaction of medial temporal lobe structures in mediating information storage.

\section{REFERENCES}

Aggleton JP, Mishkin M (1984) Projections of the amygdala to the thalamus in the cynomolgus monkey. J Comp Neurol 222:56-68.

Alvarez P, Squire LR (1994) Memory consolidation and the medial temporal lobe: a simple network model. Proc Natl Acad Sci USA 9:7041-7045.

Bolhuis JJ, Stewart CA, Forrest EM (1994) Retrograde amnesia and memory reactivation in rats with ibotenate lesions to the hippocampus or subiculum. Q J Exp Psychol 47[B]:129-150.

Buckley MJ, Gaffan D (1997) Impairment of visual objectdiscrimination learning after perirhinal cortex ablation. Behav Neurosci 111:467-475.

Cho YH, Kesner RP (1996) Involvement of entorhinal cortex or parietal cortex in long-term spatial discrimination memory in rats: retrograde amnesia. Behav Neurosci 110:436-442.

Cho YH, Beracochea D, Jaffard R (1993) Extended temporal gradient for the retrograde and anterograde amnesia produced by ibotenate entorhinal cortex lesions in mice. J Neurosci 13:1759-1766.

Cho YH, Kesner RP, Brodale S (1995) Retrograde and anterograde amnesia for spatial discrimination in rats: role of hippocampus, entorhinal cortex, and parietal cortex. Psychobiology 23:185-194.

Chow KL, Orbach J (1957) Performance of visual discriminations presented tachistoscopically in monkeys with temporal neocortical ablations. J Comp Physiol Psychol 50:636-640.

Chow KL, Survis J (1958) Retention of overlearned visual habit after temporal cortical ablation in monkey. AMA Arch Neurol and Psychiatry 79:640-646.

Eacott MJ, Gaffan D, Murray EA (1994) Preserved recognition memory for small sets, and impaired stimulus identification for large sets, following rhinal cortex ablation in monkeys. Eur $\mathrm{J}$ Neurosci 6:1466-1478.

Gaffan D (1993) Additive effects of forgetting and fornix transection in the temporal gradient of retrograde amnesia. Neuropsychologia 31:1055-1066.
Gaffan D (1994a) Dissociated effects of perirhinal cortex ablation, fornix transection and amygdalectomy: evidence for multiple memory systems in the primate temporal lobe. Exp Brain Res 99:411-422.

Gaffan D (1994b) Scene-specific memory for objects: a model of episodic memory impairment in monkeys with fornix transection. J Cognit Neurosci 6:305-320.

Gaffan D, Murray EA (1992) Monkeys (Macaca fascicularis) with rhinal cortex ablations succeed in object discrimination learning despite $24 \mathrm{hr}$ intertrial intervals and fail at matching to sample despite double sample presentations. Behav Neurosci 106:30-38.

Gaffan D, Parker A (1996) Interaction of perirhinal cortex with the fornix-fimbria: memory for objects and "object-in-place" memory. J Neurosci 16:5864-5869.

Goulet S, Doré FY, Murray EA (1998) Aspiration lesions of the amygdala disrupt the rhinal corticothalamic projection system in rhesus monkeys. Exp Brain Res, in press.

Higuchi S, Miyashita Y (1996) Formation of mnemonic neural responses to visual paired associates in inferotemporal cortex is impaired by perirhinal and entorhinal lesions. Proc Natl Acad Sci USA 93:739-743.

Hodos W, Bobko P (1984) A weighted index of bilateral brain lesions. J Neurosci Methods 12:43-47.

Kim JJ, Fanselow MS (1992) Modality-specific retrograde amnesia of fear. Science 256:675-677.

Kim JJ, Clark RE, Thompson RF (1995) Hippocampectomy impairs the memory of recently, but not remotely, acquired trace eyeblink conditioned responses. Behav Neurosci 109:195-203.

Laursen AM (1982) A lasting impairment in circle-ellipse discrimination after inferotemporal lesions in monkeys. Behav Brain Res 6:201-212.

Leonard BW, Amaral DG, Squire LR, Zola-Morgan S (1995) Transient memory impairment in monkeys with bilateral lesions of the entorhinal cortex. J Neurosci 15:5637-5659.

Levisohn LF, Isacson O (1991) Excitotoxic lesions of the rat entorhinal cortex: effects of selective neuronal damage on acquisition and retention of a non-spatial reference memory task. Brain Res 564:230-244.

Liu Z, Richmond BJ (1997) Associative learning of task progress is coded by monkey perirhinal neurons but not by TE neurons. Soc Neurosci Abstr 23:1964.

Malamut BL, Saunders RC, Mishkin M (1984) Monkeys with combined amygdalo-hippocampal lesions succeed in object discrimination learning despite $24 \mathrm{hr}$ intertrial intervals. Behav Neurosci 98:759-769.

Markowitsch HJ (1995) Which brain regions are critically involved in the retrieval of old episodic memory? Brain Res Rev 21:117-127.

McGaugh JL, Herz MJ (1972) Memory consolidation. San Francisco: Albion.

Meunier M, Bachevalier J, Mishkin M, Murray EA (1993) Effects on visual recognition of combined and separate ablations of the entorhinal and perirhinal cortex in rhesus monkeys. J Neurosci 13:5418-5432.

Murray EA (1996) What have ablation studies told us about the neural substrates of stimulus memory? Semin Neurosci 8:13-22.

Murray EA, Mishkin M (1996) 40 min visual recognition memory in rhesus monkeys with hippocampal lesions. Soc Neurosci Abstr 22:281.

Murray EA, Gaffan D, Mishkin M (1993) Neural substrates of visual stimulus-stimulus association in rhesus monkeys. J Neurosci 13:4549-4561.

Murray EA, Malkova L, Goulet S (1998) Crossmodal associations, intramodal associations, and object identification in macaque monkeys. In: Comparative neuropsychology (Milner AD, ed). New York: Oxford UP, in press.

Nadel L, Moscovitch M (1997) Memory consolidation, retrograde amnesia and the hippocampal complex. Curr Opin Neurobiol 7:217-227.

O'Boyle VJ, Murray EA, Mishkin M (1993) Effects of excitotoxic amygdalo-hippocampal lesions on visual recognition in rhesus monkeys. Soc Neurosci Abstr 19:438.

Orbach J, Fantz RL (1958) Differential effects of temporal neo-cortical resections on overtrained and non-overtrained visual habits in monkeys. J Comp Physiol Psychol 51:126-129.

Overman WH, Ormsby G, Mishkin M (1990) Picture recognition vs. picture discrimination learning in monkeys with medial temporal removals. Exp Brain Res 79:18-24.

Phillips RR, Malamut BL, Bachevalier J, Mishkin M (1988) Dissociation of the effects of inferior temporal and limbic lesions on object discrimination learning with $24 \mathrm{hr}$ intertrial intervals. Behav Brain Res 27:99-107.

Salmon D, Zola-Morgan S, Squire LR (1987) Retrograde amnesia fol- 
lowing combined hippocampus-amygdala lesions in monkeys. Psychobiology 15:37-47.

Scoville WB, Milner B (1957) Loss of recent memory after bilateral hippocampal lesions. J Neurol Neurosurg Psychiatry 20:11-21.

Squire LR, Alvarez P (1995) Retrograde amnesia and memory consolidation: a neurobiological perspective. Curr Opin Neurobiol 5:169-177.

Squire LR, Zola-Morgan S (1983) The neurology of memory: the case for correspondence between the findings for human and nonhuman primate. In: The physiological basis of memory, Ed 2 (Deutsch JA, ed), pp 199-268. New York: Academic.

Staubli U, Ivy G, Lynch G (1984) Hippocampal denervation causes rapid forgetting of olfactory information in rats. Proc Natl Acad Sci USA 81:5885-5887.

Staubli U, Fraser D, Kessler M, Lynch G (1986) Studies on retrograde and anterograde amnesia of olfactory memory after denervation of the hippocampus by entorhinal cortex lesions. Behav Neural Biol 46:432-444.

Thornton JA, Murray EA (1996) Effects of rhinal cortex lesions on retention of preoperatively learned object discriminations in rhesus monkeys. Soc Neurosci Abstr 22:1120.
Thornton JA, Malkova L, Murray EA (1997) Reinforcer devaluation is not affected by rhinal cortex lesions in rhesus monkeys. Soc Neurosci Abstr 23:499.

Vnek N, Rothblat LA (1996) The hippocampus and long-term object memory in the rat. J Neurosci 16:2780-2787.

Vnek N, Gleason TC, Kromer LF, Rothblat LA (1995) Entorhinalhippocampal connections and object memory in the rat: acquisition versus retention. J Neurosci 15:3193-3199.

Wiig KA, Cooper LN, Bear MF (1996) Temporally graded retrograde amnesia following separate and combined lesions of the perirhinal cortex and fornix in the rat. Learn Mem 3:313-325.

Winocur G (1990) Anterograde and retrograde amnesia in rats with dorsal hippocampal or dorsomedial thalamic lesions. Behav Brain Res $38: 145-154$.

Zola-Morgan S, Squire LR (1984) Preserved learning in monkeys with medial temporal lesions: sparing of motor and cognitive skills. J Neurosci 4:1072-1085.

Zola-Morgan S, Squire LR (1990) The primate hippocampal formation: evidence for a time-limited role in memory storage. Science 250:288-290. 